\title{
La causa grave para remover al socio administrador estatutario en sociedades de personas: una garantía para inversiones con valor específico
}

\author{
Pablo Manterola Domínguez*
}

\begin{abstract}
RESUMEN
El artículo estudia la regla prevista en el art. 2072 inc. $2^{\circ}$ del Código Civil chileno, conforme con esto, para remover al socio que es designado como administrador en los estatutos sociales se requiere que concurra una causa grave. El contenido de este concepto no ha sido definido por el legislador ni ha recibido una interpretación definitiva en el estado de la cuestión. Para determinar cuándo se configura una causa grave, se atiende a la lógica económica tras la elección del tipo societario y la designación de un socio como gestor privativo de la sociedad, que responde a la presencia de inversiones en prestaciones personales efectuadas por este, y que tienen un valor específico en la empresa social. Finalmente, se ofrece una descripción de algunos casos que, a la luz de esta interpretación, constituirian causa grave de remoción.
\end{abstract}

Contrato de sociedad; sociedad de personas; administrador de sociedades

\section{The serious cause for removing the manager partner nominated in the partnership agreement: a security for investments with specific value}

\begin{abstract}
This paper discusses the rule contained in the second paragraph of section 2072 of the Chilean Civil Code. Pursuant to this regulation, a "serious cause" is required in order to remove the partner designated as manager in the partnership agreement. The concept of "serious cause" is not defined by any statutory provision. Meanwhile, the courts and the scholarship have not agreed on a clear definition. To ascertain when a "serious cause" concurs, this paper argues that the economic rationale bebind some decisions made by the partners have to be considered. These are the choice of the partnership form and the designation of a partner as its sole manager, being the latter a consequence of the presence of investments consisting in the partner-manager's personal
\end{abstract}

* Licenciado en Derecho, Pontificia Universidad Católica de Chile. Doctor en Derecho, Universidad de los Andes, Chile. Profesor Asistente, Escuela de Derecho de Antofagasta, Universidad Católica del Norte. ORCID: https://orcid.org/0000-0003-0998-6382. Correo electrónico: pablo.manterola@ucn.cl.

El autor agradece las críticas y sugerencias de José Ignacio Díaz y Andrés Erbetta, así como los comentarios formulados en el Seminario de Investigación Jurídica (SIJ) organizado por la Escuela de Derecho de Antofagasta de la Universidad Católica del Norte (2 de julio de 2019).

Artículo recibido el 21.7.20 y aceptado para su publicación el 5.11.20. 
services, which have a specific value for the entrepreneurship. Finally, this paper describes some situations in which a "serious cause" would concur in light of the aforementioned interpretation.

Partnership agreement; partnership; firm manager

\section{INTRODUCCIÓN}

$\mathrm{E}$ s frecuente que los estatutos de sociedades de personas establezcan nominativamente la identidad de su administrador. Esta designación en el mismo contrato social tiene varias consecuencias jurídicas. En este trabajo nos interesa una: que la remoción del socio administrador designado en el contrato social solo se admite "en los casos previstos o por causa grave” (art. 2072 inc. $2^{\circ}$ del Código Civil, en adelante, CC).

El objetivo del presente estudio es formular algunos criterios que permitan establecer cuándo se configura una causa grave que justifique destituir al socio como administrador estatutario. El tema reviste importancia por la frecuencia con que se adopta esta cláusula, que ha sido objeto de atención en algunas sentencias recientes de nuestros tribunales superiores de justicia, que han fallado con criterios disímiles.

La hipótesis de este trabajo es que, a partir de la lógica económica de la designación de un socio administrador estatutario, debe considerarse causa grave de remoción cualquier hecho que justifica, en términos económicos, desafectar los bienes sociales a la inversión que el gestor efectúa en términos de prestaciones personales con valor específico a la empresa social. Un hecho de estas características, de haber sido previsto por socios razonables, se hubiera considerado causal suficiente para cesar al administrador estatutario, aunque ello en principio suponga la disolución de la sociedad.

Se tomará la sociedad colectiva civil como tipo societario de referencia. La razón es que el art. 2072 CC, que consagra la regla objeto de este artículo, se contiene entre las disposiciones de esta forma de sociedad, y su cabal comprensión -su interpretación legal-debe efectuarse en este contexto. No obstante, el análisis puede exportarse a otras sociedades de personas con las salvedades del caso, lo que, por otra parte, viene exigido por el dato normativo de que el art. 2072 es aplicable tanto a las sociedades colectivas como a las de responsabilidad limitada, sean civiles o comerciales.

En este trabajo se utilizará principalmente el método dogmático, es decir, se indagará el sentido del precepto para alcanzar conclusiones de lege lata, cara al ordenamiento jurídico chileno. Se recurrirá también a literatura inspirada en análisis económico, pues es útil comprender cómo se encuadra la designación de un administrador estatutario en la lógica organizacional de las reglas de la sociedad colectiva.

El trabajo se ordena del siguiente modo. Luego de ofrecer una primera interpretación del texto legal y de describir brevemente el estado de la cuestión en la doctrina y jurisprudencia nacionales (II), se argumentará cuál es la lógica económica de la designación de un administrador estatutario en el esquema de organización de la sociedad colectiva (III). A continuación se indagará en qué casos debe admitirse la remoción, tomando como punto de referencia los ejemplos que propone el legislador (IV). Finalmente, se ofrecerá las conclusiones de este estudio (V). 


\section{Planteamiento del problema en la doctrina Y JURISPRUDENCIA NACIONALES}

Es preciso comenzar con una interpretación aproximativa de la norma con el objeto de aclarar algunos de sus extremos. Luego, se revisará sumariamente los aportes doctrinales y jurisprudenciales respecto de la posición del administrador estatutario y, en particular, respecto de su remoción.

\section{Interpretación aproximativa del art. 2072: una primera lectura}

El CC parece suponer que el administrador de la sociedad colectiva será siempre un socio $^{1}$. De este modo, el art. 2072 inc. $1^{\circ}$ se refiere explícitamente al "socio a quien se ha confiado la administración por el acto constitutivo de la sociedad". No hay inconveniente en que la sociedad colectiva sea administrada por un tercero y que ese tercero sea designado en el contrato social; de hecho, una rápida revisión a los estatutos disponibles en el Registro de Empresas y Sociedades creado por la Ley $\mathrm{N}^{\circ} 20.659$, o a los extractos publicados en el Diario Oficial, permite constatar que esta situación no es infrecuente ${ }^{2}$. Sin embargo, el texto del art. 2072 inc. $1^{\circ}$ se restringe solo a aquellas personas que, además de haber sido designadas como gestoras en el instrumento estatutario, son socias. Como se verá en el siguiente apartado, esta lectura estricta de la disposición es coherente con la peculiar posición jurídica que ocupa en el contrato de sociedad ${ }^{3}$.

El "socio a quien se ha confiado la administración por el acto constitutivo de la sociedad" no puede ser removido "sino en los casos previstos o por causa grave". Una revisión somera del Registro de Empresas y Sociedades, al que ya se hizo referencia, permite comprobar que es raro que los estatutos de sociedades de personas establezcan casos en que procederá la remoción. Lo frecuente, entonces, será que deba acreditarse una "causa grave", y el texto normativo agrega que "se tendrá por tal la que le haga indigno de confianza o incapaz de administrar útilmente". Como afirma Caballero, siguiendo una sentencia de la Corte Suprema, estas dos situaciones se ofrecen solo por vía ejemplar, y no como enumeración taxativa ${ }^{4}$. En otro comentario jurisprudencial, agrega que no cualquier enfermedad que incapacite para administrar es suficiente para

\footnotetext{
${ }^{1}$ Refiriéndose a las normas correspondientes del Código de Comercio (en adelante, CCom), Olavarría, 1956, p. 65. Al abrirse el Párrafo sobre administración de la sociedad, se indica que "la administración de la sociedad colectiva puede confiarse a uno o más de los socios", y en repetidos pasajes se refiere al "socio administrador" (arts. 2073, 2074, 2077, 2078 y 2080).

${ }^{2}$ Del art. 2108 se puede desprender que no se excluye la administración por terceros, porque, si el "administrador inteligente" a que se refiere fuera uno de los socios, entonces su "pérdida" (su muerte o enfermedad) daría lugar a una causa de disolución independiente. Admiten la administración por tercero López, 1987, p. 209; Puelma, 2006, pp. 366-367.

${ }^{3}$ Cuando este estudio se refiera al administrador estatutario, deberá entenderse que, salvo indicación en contrario, se trata del socio designado como tal en el contrato social, no de terceros.

${ }^{4}$ Caballero, 2016, p. 323. La argumentación de la recurrente hacía necesaria la aclaración.
} 
remover al socio designado para este cargo 5 . Por tanto, el precepto no determina cuándo una circunstancia -sean estas que el texto indica, sea otras-constituye causa grave.

El art. 2072 inc. $3^{\circ}$ establece que "faltando alguna de las causas antedichas [causa prevista en el contrato o causa grave], la renuncia o remoción pone fin a la sociedad". Leyendo el precepto a contrario, podría pensarse que la remoción del administrador es admisible aun sin "causa grave", solo que pone fin a la sociedad. Dicha lectura no tiene sentido, porque la remoción con causa grave también pone fin a la sociedad (art. $2073)^{6}$, lo que haría ocioso acreditar una causa grave si, no habiéndola, el resultado será el mismo. La interpretación correcta es distinta: la remoción a que falta la causa grave no se admite como tal, pero puede equipararse a la renuncia a la sociedad, que dará lugar a su disolución si satisface lo previsto en los arts. 2108 a 2113: es decir, si es hecha de buena fe, en tiempo oportuno y, en el caso de sociedades de duración limitada, también por "grave motivo" (art. 2108) ${ }^{7}$. Esto último es sugerente, porque las sociedades de personas que cuentan con un administrador estatutario suelen incorporar también disposiciones que limitan su duración, de forma que la cuestión se remite a su punto de partida: si no hay causa grave para remover al administrador estatutario, tampoco la habrá para renunciar (sucesos, ambos, que pondrían fin a la sociedad). Indicio de que la causa grave del art. 2072 inc. $2^{\circ}$ y el "grave motivo" del art. 2108 inc. $2^{\circ}$ han de leerse en forma sincrónica.

La frecuencia con que coinciden la designación de un socio administrador en el contrato y la limitación de la duración de la sociedad, permite entender en qué casos presta utilidad la remoción de aquel por causa grave. Porque, de otro modo, ¿qué sentido podría tener un litigio para pedir la remoción del administrador estatutario, en lugar de renunciar a ella -supuesta la buena fe y el tiempo oportuno-? Si la sociedad se ha pactado con duración indefinida, desde luego, no tiene sentido alguno; solo lo tiene en sociedades en que se restrinja la posibilidad de renuncia, sea en forma expresa, sea porque -al menos formalmente- la sociedad se celebra con una duración limitada ${ }^{8}, y$

${ }^{5}$ Para evaluar este problema, Caballero asume un principio de continuidad de la administración, que induce desde las reglas de la sociedad anónima, y que justificaría aplicar la regla supletoria del mandato tácito y recíproco: Caballero, 2014, p. 369. Sin embargo, deja pendiente ofrecer un criterio que permita equiparar ese impedimento temporal a la omisión de su designación, acerca de lo que el autor no se pronuncia debido a que el caso comentado justificaba esa equivalencia: CABALLERo, 2014, p. 371.

${ }^{6}$ El CC lo expresa de modo distinto, aunque equivalente: "en el caso de justa renuncia o justa remoción del socio administrador designado en el acto constitutivo, podrá continuar la sociedad, siempre que todos los socios convengan en ello" y en un nuevo régimen de administración (art. 2073). Si el administrador ha sido destituido por causa grave, difícilmente podría alcanzarse esa unanimidad.

${ }^{7}$ Es discutible si debiera admitirse cuando el contrato social ha excluido el derecho de cada socio a poner término unilateral por medio de renuncia. Una interpretación restrictiva podría justificarse porque, de otro modo, el socio de una sociedad con administrador estatutario encontraría un cómodo expediente para ponerle fin unilateralmente, sin respetar los requisitos de la renuncia y aun cuando el contrato hubiera excluido el derecho a renunciar: remover al gestor invocando cualquier trivialidad.

${ }^{8}$ Como cuando se pacta la sociedad por un plazo fijo de cierta cantidad de años, prorrogable automáticamente salvo comunicación en contrario del propio administrador. Así se establecía en la sociedad a que se refirió la Corte Suprema, 26.10.2012, rol 1008-2010 (en este caso era una comandita simple). El 
entonces solo puede renunciarse a ella por "grave motivo" (art. 2108). Entre los ejemplos de motivo grave que enuncia el art. 2108, se encuentra "la pérdida de un administrador inteligente que no pueda reemplazarse entre los socios", lo que invita a pensar en el administrador estatutario9. "Causa grave" y "grave motivo" parecen las dos caras de una misma moneda.

\section{Posición jurídica del administrador estatutario en la doctrina}

En Chile, se asume como punto de partida que los textos codiciales respecto de administración de sociedades de personas recogen la llamada "teoría del mandato" ${ }^{10}$. El CC daría pie a esta conclusión en varias de sus disposiciones, como el art. 2077 CC, que se refiere al "mandato" que recibe el socio administrador (sin distinguir si fue designado en estatutos o en un acto posterior). Sin embargo, varios autores puntualizan que la aplicación directa de las reglas del mandato no es admisible sin algunas salvedades ${ }^{11}$, especialmente respecto del administrador estatutario. En efecto, la designación del gestor en el acto constitutivo es signo de que su identidad ha sido considerada como esencial al celebrar el contrato social ${ }^{12}$, con consecuencias ajenas a las que correspondería de aplicar las reglas del mandato ${ }^{13}$. En esta línea, Jequier enfatiza la "posición constitucional" del gestor designado en el contrato social, con referencia a la doctrina española que a continuación se reseñará ${ }^{14}$. En todo caso, recientemente Reveco e Iglesias

árbitro primero, luego la Corte de Apelaciones de Santiago y finalmente la Corte Suprema, coincidieron en que esta sociedad se encontraba sujeta a plazo y que, por consiguiente, debía excluirse la renuncia ad nutum del art. 2108, pretendida por el demandante. Tentativamente, puede advertirse que el art. 2108 no se refiere a la sociedad sujeta a plazo, sino a la sociedad que "se ha contratado por tiempo fijo". Y en este caso, ese plazo prorrogable no es un "tiempo fijo", sino un plazo incierto. Véase un argumento semejante en QuesaDA, 1991, p. 46.

${ }^{9}$ El proyecto de 1846-1847 no contenía la regla hoy establecida en el art. 2072, ni las que le siguen, sino únicamente la distinción entre administrador estatutario y mandatario, que hoy enuncia el art. 2071. Sí se comprendía la disposición del actual art. 2108 (art. 505), tomada del art. 1871 del CC francés: BELLO, 1887 , p. 549. Esta situación cambia en el proyecto llamado inédito. Bello decide prestar más atención al gerente de la sociedad colectiva, luego de revisar la opinión de algunos comentadores del art. 1871 del CC francés (el editor referencia los comentarios de Troplong y de Duranton). Abre así un nuevo párrafo sobre su administración, y agrega, entre otras disposiciones, el art. 2250a acerca de renuncia y remoción del administrador estatutario (art. 2072 CC): Bello, 1890, p. 521 . Además, en el art. 2285 del proyecto inédito (art. 2108 CC), Bello agrega como nuevo ejemplo de motivo grave "la pérdida de un administrador intelijente que no pueda reemplazarse entre los socios": BELLO, 1890, p. 532. Estos datos permiten concluir que la "causa grave" del art. 2072 el "motivo grave” del art. 2108 tienen la misma inspiración.

10 Además de los autores citados a continuación, VÁsquez, 2015 b, p. 419.

${ }^{11}$ Puelma afirma que la teoría del mandato regiría solo en cuanto al problema de la representación de la sociedad: Puelma, 2006, pp. 359-361.

\footnotetext{
12 Puelma, 2006, p. 373.

13 JEQuier, 2014, pp. 171-174.

${ }^{14}$ Jequier, 2014, p. 183.
} 
afirman la necesidad de aplicar las reglas del mandato a esta situación ${ }^{15}$, pues, si bien el administrador estatutario tiene un verdadero derecho a administrar, se halla en tal subordinación a los intereses de la sociedad, que sus facultades corresponden más bien a un "derecho-función"16.

En el ámbito español ${ }^{17}$, se indica que la administración de quien es designado en estatutos tiene un carácter privativo, a diferencia de la gestión por personas individualizadas en acto posterior, que Paz-Ares designa como administración "funcional". Lo propio de la administración privativa es la "esencialidad del ligamen entre el interés a participar como socio y el interés a administrar" ${ }^{18}$, de forma que el gestor no solo tiene un deber de administrar, sino también un verdadero derecho a hacerlo, emanado del contrato social. De ahí que, respecto de este administrador, la aplicación siquiera analógica de las reglas del mandato sea casi siempre inadecuada, porque no puede decirse que un mandatario tenga un derecho a administrar, sino que su posición es esencialmente subordinada a los intereses del mandante ${ }^{19}$.

Siguiendo a Jequier, esta forma de comprender la administración de quien es designado en estatutos parece la más acertada. Y es, como se verá en este trabajo, coherente con la regla establecida en el inc. $2^{\circ}$ del art. 2072, así como con la lógica económica que subyace a ella.

\section{Doctrina y jurisprudencia sobre la calificación de la causa grave}

La remoción del administrador estatutario no ha sido objeto de una atención detenida. Puelma guarda silencio acerca del punto, aunque, refiriéndose a una justa causa de renuncia -que el precepto no prevé-, la relaciona con la equidad ${ }^{20}$. Vásquez parece referir la equidad también a la remoción ${ }^{21}$. Sin embargo, es fácil ver que remisiones a la equidad no son suficientes para resolver, en concreto, cuándo se está ante una causa grave. Para comprender la función de este concepto y dotarlo de contenido, se ha acudido a distintas fuentes.

En primer lugar, el recurso a la noción de confianza, de que se vale el art. 2072 inc. $2^{\circ}$, permite preguntar si debiera equipararse la causa grave a la pérdida de confianza entre las partes, tradicionalmente asociada al affectio societatis, y así se ha fallado

${ }^{15}$ Reveco e Iglesias, 2019, p. 157. Sobre la estructura de los derechos-función con referencia a la administración de sociedades, véase PARDow, 2007, pp. 98-103.

${ }^{16}$ Reveco e Iglesias, 2019, pp. 164-166. Caballero, por su parte, afirma que existe un deber de lealtad de mayor "intensidad” en el administrador estatutario: CABALlERo, 2016, p. 323.

${ }^{17}$ El CC español establece en su art. 1692 una disposición similar, aunque más escueta, al art. 2072 de nuestro CC.

18 PAZ-Ares, 1991, p. 1450.

19 PAZ-Ares, 1991, pp. 1451-1456. Véase también Fernández de la Gándara, 1977, pp. 405407. Esa subordinación es lo que Pardow, describiendo los derechos-función, llama un "principio altruista": PARDOW, 2007, p. 102.

${ }^{20}$ Puelma, 2006, p. 378.

21 VÁsQuez, 2015b, p. 420. 
en algunas sentencias ${ }^{22}$. Sin embargo, la confianza en general, o la affectio societatis en particular, no parecen ofrecer utilidad para resolver el problema ${ }^{23}$, como se ha resuelto en otra jurisprudencia ${ }^{24}$. Por su parte, nada se resuelve reemplazando un concepto de contenido indeterminado (causa grave) por otro (affectio societatis). Además, si el administrador privativo ocupa esa posición constitucional a que anteriormente se aludió, y tiene un verdadero derecho a ejercer su gestión, para destituirle no debiera bastar "una simple pérdida de confianza" 25 . Prescindir, al menos en este problema, de la confianza y del affectio societatis, sería coherente con alguna autorizada doctrina, que tiende a restar relevancia al carácter intuitu personae de las sociedades de personas ${ }^{26}$.

Cabría entonces restringir la causa grave de remoción a la infracción a deberes de lealtad por parte del administrador. Olavarría, citando una antigua sentencia, afirmaba que la causa grave se configura cuando el administrador actúa con dolo o al menos con culpa grave ${ }^{27}$. Más recientemente, Caballero ha argumentado la calificación de infracciones al deber de lealtad como causa grave de remoción, al menos para ciertos $\operatorname{casos}^{28}$, siguiendo en esto una opinión de la Corte Suprema ${ }^{29}$. Esta perspectiva es, sin embargo, insuficiente, pues la causa grave no se agota en el hacerse "indigno de confianza", sino que comprende circunstancias tales como hacerse "incapaz de administrar útilmente", y aun otras que la norma no se cuida de precisar. Además, ¿cómo compatibilizar la existencia de esos deberes de lealtad -con lo que significan de subordinación del propio interés en

${ }^{22}$ Corte Suprema, 12.07.2010, rol 7574-2008. Al dictarse sentencia de reemplazo, se acogió la apelación en los términos en que lo había hecho la Corte de Apelaciones de San Miguel, 14.08.2008, rol 536-2007. Esta, por su parte, acogió la acción de remoción del administrador estautario pues, pese a no acreditarse infracciones que puedan calificarse como graves bajo el art. 2072, es posible apreciar una enemistad entre los socios $\left(\mathrm{cdo} .11^{\circ}\right.$ ) que denota una falta de affectio societatis, definido como "una disposición de la voluntad [...] que represente el ánimo de subordinar el interés individual y personal de cada uno de los socios al interés general o social" (cdo. $12^{\circ}$ ). Se agrega que "los socios se han perdido el mutuo respeto, que entre ellos reina la desarmonía y la animadversión, que no existe espíritu de colaboración y se han perdido la confianza recíproca, lo que hace aconsejable el cambio del administrador de la sociedad" (cdo $13^{\circ}$ ). En sentido muy próximo, la Corte de Apelaciones de Antofagasta ha fallado que un conflicto de interés es suficiente para justificar la desaparición de la confianza de los demás socios en el administrador estatutario, la que, en cuanto menoscaba la affectio societatis, constituye una causa grave que permite removerle: Corte de Apelaciones de Antofagasta, 29.04.2015, rol 1500-2014 (confirmada, pero con distinto fundamento, en la sentencia citada en la nota 24).

23 Caballero, 2016, p. 326.

${ }^{24}$ La propia Corte Suprema, en contraste con la primera sentencia citada en nota 22, advierte que al fallar "ha hecho abstracción del antecedente subjetivo, que puede tener una connotación personal para quien la sufre, pero que no altera las circunstancias objetivas de los hechos" que hacen indigno de confianza al administrador. Expresamente también, se prescinde de todo lo relativo a la affectio societatis, pues para resolver basta acudir al texto del art. 2072 CC: Corte Suprema, 11.07.2016, rol 9046-2015, cdo. 26².

25 PAZ-Ares, 1991, p. 1460.

${ }^{26}$ Fernández de la Gándara, 1977, pp. 371-381; Pantaleón, 1993, p. 47.

27 Olavarría, 1956, pp. 66-67 (la sentencia citada no lleva referencia).

${ }^{28}$ Caballero, 2016, pp. 321-322.

29 Así, afirmó que el administrador estatutario, al alegar la existencia de un crédito cuantioso cuyo acreedor sería una persona relacionada con él y cuyo deudor serían los demás socios de la sociedad administrada, le sitúa en un conflicto de interés suficiente para estimarle "indigno de confianza" en los términos del art. 2072 inc. $2^{\circ}$ : Corte Suprema, 11.07.2016, rol 9046-2015, cdo. $26^{\circ}$. 
favor del de terceros- con la posición constitucional del administrador privativo, y el consecuente derecho a administrar la sociedad?

Solo resta reconducir la causa grave a un contexto más amplio: el de una excepción a la intangibilidad del contrato, que, como tal, habría de interpretarse de forma restrictiva ${ }^{30}$. Y así, del contenido material del concepto de causa grave podría decirse lo que Paz-Ares de la "causa legítima”, según la redacción de la norma equivalente en el CC español: "mediará causa legítima bastante para la revocación siempre y cuando a los socios no se les pueda razonablemente exigir que toleren o soporten conductas del administrador que van en detrimento de la sociedad", sea en la forma de incumplimientos graves o de una manifiesta incapacidad ${ }^{31}$.

Ha de reconocerse que, con esto, no se ha avanzado mucho. Sin embargo, vincular las reglas pertinentes al administrador estatutario con la intangibilidad del contrato, y, consecuentemente, afirmar que el gestor goza de un auténtico derecho a administrar (y no simplemente de un derecho-función), es un buen punto de partida para el objeto de este estudio. Contribuye a explicar por qué el régimen de remoción del administrador estatutario se aparta visiblemente de las reglas del mandato (contrato que termina por la renuncia o revocación de cualquiera de las partes, sin necesidad de que concurra una justa causa). Pero es solo un punto de partida.

\section{LÓGICA ECONÓMICA DE LA DESIGNACIÓN DE ADMINISTRADOR ESTATUTARIO}

Para determinar cuándo procede la remoción del socio administrador estatutario, el dato de que los demás socios le han retirado su confianza es, como se ha visto, insuficiente. A diferencia de lo que sucede en el mandato, la mera confianza no basta para explicar la designación de un administrador estatutario, pues esa confianza es solo el reflejo de que su posición constitucional es funcional a las características de la inversión realizada y del negocio emprendido. Son estas características objetivas, y no una confianza subjetiva, las que realmente determinan cuándo un evento puede calificarse como causa grave y justificar la remoción del gestor.

${ }^{30}$ PAZ-Ares, 1991, p. 1460. En este sentido, si bien obiter dicta, frente al argumento de que la remoción implicaría desconocer lo pactado, la Corte Suprema ha fallado que la designación de un administrador estatutario efectivamente es ley para las partes, pero que ello no obsta a removerle por causa grave acreditada por un socio: Corte Suprema, 11.07.2016, rol 9046-2015, cdo. 32. En otro fallo, la Corte de Apelaciones de Santiago aplicó un criterio tomado directamente del derecho de los contratos para rechazar la remoción: "estando acreditado que ambas partes incumplieron el contrato [social], no procede en derecho declarar la remoción de su cargo, atendidos los incumplimientos mutuos”: Corte de Apelaciones de Santiago, 3.05.2013, rol 5676-2001, cdo. 6º . La Corte Suprema casó de oficio esta sentencia, y en sentencia de reemplazo confirmó el laudo, sin agregarle otros razonamientos en cuanto a la remoción del administrador: Corte Suprema, 20.06.2014, rol 4341-2013.

${ }^{31}$ PAZ-Ares, 1991, p. 1460. 
Para mostrar lo anterior, se analizará la lógica económica tras la elección del tipo societario por parte de los socios, y específicamente, la lógica de la designación de uno de ellos como administrador privativo. De ningún modo se trata de reducir a esta lógica económica las variadas razones que conducen a elegir el tipo de la sociedad civil (colectiva o, más frecuentemente, de responsabilidad limitada) y a incorporar en sus estatutos la designación del gestor. El intento de este capítulo es, más bien, mostrar una razón, no necesariamente la principal, para adoptar estas reglas de organización. Se trata, no obstante, de una que se edifica sobre la lógica interna de las reglas de organización, y no sobre aspectos exteriores a ella (ventajas tributarias, menor costo de constitución, desformalización de sus órganos). Presupuesta la presencia de socios racionales y de un legislador igualmente racional, esta razón tendrá especial aptitud para orientar la interpretación de los preceptos que integran el entramado de reglas en que consiste la forma organizacional, y dentro de ellas, la del art. 2072 inc. $2^{\circ}$, objeto de este estudio.

\section{Las reglas de la sociedad de personas responden a la relevancia de la inversión en prestaciones personales con valor específico en la empresa social}

La decisión de organizar una empresa común bajo uno de los varios esquemas que ofrece la legislación es susceptible de un análisis económico. Desde la relación informal pero continuada entre los agentes, hasta la sociedad anónima cuyas acciones gozan de amplia circulación en un mercado secundario, pasando por los contratos de larga duración, las sociedades de personas y las sociedades anónimas cerradas, cada alternativa tiene ventajas y desventajas que agentes racionales ponderarían al emprender un negocio. Esta elección ha sido presentada como una disyuntiva entre una mayor adaptabilidad de la organización hacia las necesidades individuales de cada agente (lo que reduce el margen de oportunismo para la mayoría, o para quienquiera que tenga el control); y una mayor adaptabilidad de la organización hacia las necesidades de la empresa colectiva (lo que, a la inversa, reduce el margen para un actuar oportunista de cada agente individual) ${ }^{32}$. El cuadro de las formas de organización se ofrece así como un espectro, como una escala de grises que recoge multitud de matices.

Si existiera una forma de organización absolutamente mejor que las demás, la variedad de tipos societarios no encontraría otra justificación que el desarrollo histórico de las instituciones, y las figuras del pasado quedarían arrumadas en los manuales de derecho de sociedades - como de hecho ha ocurrido con algunas de ellas ${ }^{33}$-. Sin embargo, fuera de una mayor prevalencia de unas formas sobre otras, los emprendedores optan todavía por una diversidad de modalidades de organización, pues negocios cualitativamente diversos exigen reglas también diversas. Para comprender cómo esa diversidad

32 O'Kelley, 1992, p. 219. Naturalmente, el autor no se refiere a sociedades de personas ni a sociedades anónimas, sino a partnerships y corporations, pero su proximidad con las figuras del derecho continental es suficiente como para justificar la equivalencia en este argumento.

33 Acerca del tema, véanse, entre otros, VÁsquez, 2015a, p. 86, y, en relación con sociedades de personas, las indicaciones que ofrece AlCAlde, 2018, pp. 414-415. 
cualitativa condiciona la elección de la forma organizacional, presta utilidad el concepto de inversiones con valor específico ${ }^{34}$.

Una inversión tiene un valor específico cuando su valor en la empresa es significativamente superior a su valor fuera de ella. Por ejemplo, la instalación industrial que permite procesar y enlatar anchoveta, probablemente no tiene muchos usos alternativos fuera de la empresa pesquera que realiza sus labores en las cercanías (a diferencia del dinero, bien fungible por antonomasia). Poner énfasis en la adaptabilidad de la empresa a las necesidades individuales de cada agente, por ejemplo, permitiéndole exigir a voluntad la liquidación parcial o total de la empresa, pondría en peligro el valor específico de las inversiones ${ }^{35}$.

El concepto de especificidad puede predicarse también de prestaciones personales ${ }^{36}$. Conocer el comportamiento del mercado de bebidas cola en una ciudad tiene un valor específico, cuando se asocia a los derechos de representación de una marca de bebidas cola en esa misma ciudad: quizás ese conocimiento no sirve a ningún otro objeto -ni tiene valor alguno- si se carece de los derechos de representación. Si quien posee conocimientos y derechos de representación es la misma persona, quizás podría desarrollar el negocio individualmente. Pero si se trata de personas distintas querrán asociarse, y entonces cobra relevancia la necesidad de efectuar inversiones con valor específico: uno de los socios dedicará tiempo y energías al desarrollo de conocimiento sobre el mercado de bebidas cola en una ciudad, dejándole, de este modo, cautivo de aquel otro socio que es titular de los derechos de representación, por la pérdida de valor específico que implicaría desvincularse.

Las reglas por defecto de la sociedad de personas son funcionales a una inversión en capital humano con valor específico, efectuada por todos los socios de forma más o menos equilibrada, cuya magnitud es mayor que la del valor específico de los activos de la sociedad ${ }^{37}$. Esta forma de organización limita la exposición al oportunismo de la mayoría, porque las modificaciones fundamentales se adoptan por unanimidad, y porque cada socio puede renunciar a la sociedad provocando su disolución (el activo se repartirá entre todos). El costo de este esquema es una menor adaptabilidad colectiva, precisamente porque la regla de unanimidad abre un espacio al oportunismo individual; pero este costo es moderado, pues la relativa insignificancia de la especificidad del activo en

${ }^{34}$ Acerca de este concepto fundamental para el análisis económico de las organizaciones, véase, por todos, Williamson, 1985, pp. 30-35.

${ }^{35}$ Alfaro, 1998, pp. 94-95. Los costos de liquidar existen, incluso, cuando uno de los socios se adjudica la empresa social como unidad económica, según advierte en ese lugar el autor citado. En este trabajo se utilizará el concepto de liquidación con alguna libertad, como sinónimo de desvinculación o desorganización de los factores de producción, sea que adopte los contornos jurídicos de la partición, sea que se proceda mediante una liquidación en sentido estricto.

36 El punto ya había sido advertido, entre otros, por MARSCHAK, 1968, p. 14. Con prestaciones personales me referiré a cualquier servicio o cualidad de carácter intelectual o intangible que es provista por los socios, y que tiene un valor en la empresa: conocimientos técnicos, secretos empresariales, relaciones comerciales o familiares, prestigio relevante para el desarrollo del negocio, etcétera.

${ }^{37}$ O’Kelley, 1992, p. 230. Véase también Ribstein, 2004, pp. 212-213. 
relación con las prestaciones personales hace que la amenaza del bloqueo pueda conjurarse con la amenaza contraria de disolver la sociedad, que destruiría el valor específico de aquellas prestaciones. En palabras sencillas, cada socio de una sociedad de personas puede decirse: "me preocupa menos tener que desarmar la sociedad y desorganizar sus activos, a ser dejado al margen de las decisiones y que los demás puedan disponer a su arbitrio de mis conocimientos, mis relaciones o mi prestigio”.

Naturalmente $-\mathrm{y}$ esta es una de las ventajas de este modelo ${ }^{38}-$, las empresas no se corresponden precisamente con alguno de los compartimentos estancos que provee el sistema de tipos societarios. Cada negocio puede ocupar cualquier punto dentro de la escala de grises: sus inversiones son más o menos específicas, en ellas prepondera más o menos la especificidad de los servicios personales o de los activos físicos, los servicios personales son provistos en distinta medida por las partes del negocio. Esta variedad exige entender la decisión respecto de las formas de organización de manera incremental (la empresa se corresponde "más o menos" con el tipo societario); además, permite comprender que los agentes puedan modelar el tipo societario elegido mediante estipulaciones que atenúen marginalmente sus reglas, como la cláusula de continuar la sociedad en caso de fallecimiento de un socio; la duración limitada pero prorrogable, que evita una denuncia ad nutum; la cesibilidad de los derechos sociales, quizás con ciertos límites; y -la que aquí nos interesa- la designación de un administrador estatutario.

Como se puede ver, esta perspectiva prescinde de toda consideración a una especial disposición subjetiva en quienes forman la empresa social. Para explicar por qué se ha constituido una sociedad de personas, no se precisa suponer una affectio societatis, entendida como "manifestación de espíritu de equipo" y "elemento sicológico o intencional" que "engendra una estima recíproca entre los socios" 39. Sí es preciso, en cambio, suponer un compromiso, esto es, un contrato. Esta perspectiva es coherente, por tanto, con aquella tendencia de alguna doctrina a restar relevancia al carácter intuitus personae de las sociedades de personas ${ }^{40}$, de que antes se advirtió.

\section{La designación del administrador estatutario como garantía para quien realiza una mayor inversión de prestaciones personales con valor específico}

Recordemos que, si bien no hay inconveniente en que la sociedad colectiva sea administrada por un tercero, el CC parece suponer que el administrador será siempre un socio. Desde luego, el art. 2072 inc. $1^{\circ}$ se refiere explícitamente al "socio a quien se ha confiado la administración por el acto constitutivo de la sociedad". Pues bien, este socio administrador realiza una inversión no solo por medio de un aporte patrimonial, sino también en prestaciones personales. Bien puede ocurrir, pero no es indispensable para el análisis, que sus tareas como administrador constituyan justamente su aporte

\footnotetext{
38 Como destaca O'Kelley, 1992, p. 253.

${ }^{39}$ López, 1987, p. 218.

40 Fernández de la Gándara, 1977, pp. 371-381; Pantaleón, 1993, p. 47.
} 
en la industria, pero también realiza una inversión cuando desarrolla conocimientos, contactos o redes con valor específico al administrar la sociedad, aun cuando careciera de aquellos al tiempo de constituirse.

El valor específico de estos servicios, conforme con el esquema anteriormente descrito, es más significativa que el valor específico de los activos de la sociedad. De otra forma, lo razonable habría sido optar por una sociedad de capital, en que no basta la sola decisión de una persona para desafectar los bienes sociales al objetivo empresarial. Al mismo tiempo, si al celebrar el contrato este socio ha exigido administrar privativamente la sociedad, y los demás han consentido en ello, es que esas prestaciones personales con valor específico no serán provistas por todos los socios, o no de forma equilibrada: el administrador estatutario ha comprometido prestaciones personales con valor específico en mayor medida que los demás.

En efecto, la regla legal de administración colectiva o mandato tácito y recíproco (a que conduciría la libre revocabilidad del gestor mandatario) expone el valor específico de esa inversión a una expropiación oportunista por la mayoría. El gestor, que ha puesto al servicio de la sociedad sus conocimientos, contactos, relaciones o prestigio, y que ha dejado de aplicarlos a otros negocios para consagrarlos a la empresa común, vería cómo los demás socios se apropian su valor, por ejemplo, obstruyendo su aplicación al objeto social (art. 2081 reglas $1^{\mathrm{a}}$ y $4^{\mathrm{a}}$ CC) o disponiendo de los bienes en que se ha incorporado aquella información, al margen de la sociedad (regla $2^{\mathrm{a}}$ ). Y aun fuera de ese actuar oportunista, la intervención de los demás socios en los negocios sociales expondría el valor específico de esa inversión, al adoptar decisiones desacertadas precisamente por carecer de la experiencia del administrador estatutario (y esta posibilidad les daría una herramienta con que extorsionar a aquel socio en una renegociación oportunista).

Visto el problema ex ante, la designación como administrador privativo sirve de garantía para aquel socio: desarrollará aquellas prestaciones personales e incorporará a los bienes sociales su valor, pero se asegura de que serán aplicados exclusivamente a la empresa social por la persona más indicada -él mismo-, y de que redituarán en favor de todos los socios. Sus consocios siempre podrán recuperar su propia inversión si renuncian a la sociedad y generan así su disolución, pero lo harán solo si el valor de esos bienes cuando son administrados por el socio gestor, es inferior al valor de la segunda mejor inversión de esos bienes (lo que exigirá perder el valor específico e incurrir en los costos de liquidación). Y si la posibilidad de renuncia se encuentra limitada, como sucede frecuentemente, entonces deberán invocar un grave motivo, según prescribe el art. 2108.

Esta perspectiva puede ser complementaria con suponer que los demás socios han contratado en atención a la identidad del administrador. En efecto, ellos han depositado su confianza en el socio administrador, porque este así lo exigió al entrar en la sociedad; el socio administrador, por su parte, también realiza un acto de confianza cuando compromete aquellas prestaciones personales con valor específico. Y esta confianza recíproca da lugar a un compromiso, en donde el CC reconoce la fuerza del contrato. La cláusula de designación de un administrador privativo se entiende perfectamente, tanto si los socios se unen por un parentesco, por amistad, por una dilatada experiencia 
compartida en los negocios, como si falta esa peculiar relación. De ahí que, como anota Caballero, el concepto de affectio societatis sea extraño a la lógica del administrador estatutario $^{41}$.

Esta forma de entender la administración privativa subraya que el socio gestor no es solamente un fiduciario respecto de sus consocios. A diferencia tanto de quien ejecuta un mandato como del administrador designado en acto posterior, la posición del administrador estatutario no lo ubica en una completa subordinación de intereses frente a la sociedad y a los demás socios, porque la administración es para él no solo una obligación sino también el ejercicio de un derecho. Tanto él como sus consocios han considerado la cláusula como esencial para la decisión de contratar. Tiene, pues, un interés propio en gozar de sus facultades -y en no ser despojado de ellas-.

Ocurre, sin embargo, que la intangibilidad de esta disposición contractual debe adecuarse a la realidad de la sociedad. Se trata de un negocio que se prolonga en el tiempo, con la necesidad de ser ajustado a variaciones significativas en las circunstancias que pudieron tenerse a la vista al contratar. Adicionalmente, este contrato comprende todo aquello que es preciso para llevar a cabo una empresa en común, y no podría ser materia de acuerdos expresos sin incurrir por ello en costos que harían prácticamente imposible su celebración. Sería difícil prever cada caso en que los socios estarían dispuestos a coadministrar la sociedad o a designar a un mandatario, es decir, en que se justificaría económicamente desafectar los bienes de la sociedad a la actividad de aquel socio que incorporará prestaciones personales con valor específico. A falta, pues, de las previsiones estatutarias que el propio art. 2072 inc. $2^{\circ}$ permite incorporar, el legislador permite que el juez acoja una demanda de remoción, cuando concurre una "causa grave" 42 .

\section{Situaciones atípicas}

Lo indicado en los dos apartados anteriores es una inducción de cierta lógica económica, a partir de la elección del tipo social y de las cláusulas del contrato. Como se advirtió al comenzar este capítulo, en la realidad las razones que justifican esa elección son bien dispares. Sumariamente se indicará algunas situaciones que no cuadran con la descripción anterior, en las que ha de verse un indicio de que han primado razones de otra índole.

Es posible que en estatutos se designe como administrador a un tercero. Este, aunque designado en el contrato social, debe ser tratado como "administrador funcional",y puede renunciar y ser revocado como un mandatario común. Desde luego, el art. 2072 se refiere únicamente al socio que es designado como administrador en el contrato social; además, este tercero no puede tener un interés en administrar que se funde en el contrato social,

41 Caballero, 2016, p. 326.

${ }^{42}$ Como se puede ver, tiene lugar aquí el problema de contratación incompleta que atraviesa el derecho societario, y que exige del juzgador llenar, con previsiones contractuales hipotéticas, los conceptos abiertos de que se sirve la legislación: por todos, Alfaro, 1995, pp. 22-32. 
pues no es parte de este último, ya que no ha efectuado un aporte. Por el contrario, es razonable considerarle en una posición fiduciaria, esencialmente subordinada a los intereses de los demás socios, equivalente a la del mandatario ${ }^{43}$.

Es asimismo posible que los estatutos sociales designen como administrador no a uno o a varios socios, sino a todos ellos. La designación de los administradores no obedecería entonces a una diversa proporción en que desarrollan prestaciones personales con valor específico a la empresa, ni que para cada uno de ellos dicha designación constituya una garantía de que esa inversión no será expropiada ni destruida por los demás ${ }^{44}$.

Finalmente, la estructura de las sociedades por acciones se corresponde con las sociedades de capital, pero la ley admite un amplio margen para la libre configuración del contrato. Esta libertad comprende la elección del régimen de administración, lo que permitiría dotarla de un socio gestor designado en estatutos, como de hecho ocurre frecuentemente ${ }^{45}$. En tal caso, y si los estatutos nada dicen, podría discutirse si puede destituirse al administrador cuando concurre causa grave, o si, por el contrario, será preciso acudir a la acción de disolución por causa grave prevista en el art. 105 de la Ley N 18.046 sobre Sociedades Anónimas (de aplicación supletoria a este tipo social). En cualquier caso, la peculiar estructura organizacional de las sociedades de capital impide identificar aquí las razones económicas que se ha expuesto en los apartados anteriores, con las consecuencias para la interpretación del concepto de causa grave que se exponen a continuación ${ }^{46}$.

\section{CuÁndo debe AdMitirse la REMOCión DEL ADMINISTRAdor}

El encuadre de la designación del administrador estatutario en la lógica económica de la organización de una sociedad de personas ilumina cuándo un determinado hecho puede justificar su remoción. Desde la óptica descrita en el capítulo anterior, debe

43 Únicamente se plantea la duda cuando el administrador designado en los estatutos es un tercero desde un punto de vista formal, pero en la realidad de los intereses en juego, se trata del propio socio. Ocurre en ocasiones que una sociedad, entre cuyos socios se cuenta una empresa individual de responsabilidad limitada, tiene como administrador estatutario al constituyente de esta empresa. Tentativamente, en casos como este cabría dar aplicación al art. 2072 inc. $2^{\circ}$ por analogía.

${ }^{44} \mathrm{La}$ designación de todos los socios como administradores pudo observarse en las sentencias de la Corte Suprema, 25.06.2013, rol 6846-12; y 11.07.2016, rol 9046-2015. En una y otra, los estatutos preveían que la sociedad sería administrada por los dos únicos socios, y que, en caso de muerte de alguno, la sociedad continuaría con la sucesión del fallecido (conforme al art. 2105 CC). En el primer caso, solo se establecía que la sucesión no podría ejercer la administración de la sociedad; en el segundo caso, se designaba para cada administrador un suplente (para cada socio, un tercero pariente cercano suyo). La previsión de la muerte de un socio con la consiguiente entrada de sus herederos (cuando así se ha previsto), puede volver útil la designación de todos los socios como administradores estatutarios cuando uno de ellos fallezca -para excluir de la administración a herederos con quienes no se contrató-.

45 Véase el reciente estudio empírico de Caballero y Pardow (2020), p. 311.

46 De los problemas que suscita la modificación convencional del régimen de administración de las sociedades por acciones, Caballero y PARdow (2020), pp. 315-317. 
comprenderse también aquellos hechos que hacen razonable, en términos económicos, desafectar los bienes sociales a la inversión que el administrador efectúa en términos de prestaciones personales con valor específico a la empresa social, valor que, por lo tanto, se perderá. Socios razonables hubieran incorporado explícitamente estos hechos como causales de remoción si, desde un punto de vista práctico, hubieran podido preverlos en el contrato social. Para concretar este aserto, se indicarán algunos casos que típicamente cumplen con esa descripción, y se los vinculará con los que, a modo ejemplar, sugiere el mismo art. 2072 inc. $2^{\circ}$.

\section{Deslealtad o grave negligencia del administrador: hacerse "indigno de confianza"}

Si la designación del gestor se explica como un gesto de recíproca confianza objetivamente exigida por la naturaleza de la inversión efectuada, no es difícil admitir que conductas del administrador que la traicionen son causa suficiente para destituirle. Razonablemente, los demás socios no esperarán que aquel a quien designaron como administrador incorpore de forma honesta su actividad en los negocios sociales, con el objeto de aumentar el valor de la empresa en marcha, si de hecho actúa oportunistamente (por ejemplo, con la amenaza de cobrarse deudas personales en bienes de la sociedad, o con la constitución de empresas paralelas para capturar oportunidades de negocio, dos situaciones que se han presentado a la jurisprudencia). No es justo que esos socios deban esperar a que las conductas se hagan reiteradas o adquieran entidad suficiente como para acabar de arruinar los activos sociales. El administrador se ha hecho, al decir del art. 2072, "indigno de confianza”, lo que significa algo más que un unilateral retiro de confianza por parte de sus consocios ${ }^{47}$.

La administración meramente negligente no puede recibir el mismo tratamiento, salvo cuando la culpa sea de tal magnitud que el gestor se haga también, objetivamente, indigno de confianza. Para emplear las categorías anteriormente expuestas, un descuido en la administración del negocio social no autoriza a los demás socios a intervenir en ella, de modo que puedan apropiarse o destruir el valor de las prestaciones personales que aquel ha comprometido y desarrollado en la gestión de la sociedad, dando lugar a una disolución y posterior partición o liquidación (art. 2073 CC). O, más bien, esos socios pueden hacerlo, pero solo bajo las reglas de la renuncia: de buena fe y en tiempo oportuno; y en las sociedades de duración limitada, concurriendo causa grave ${ }^{48}$.

Esta exclusión de la administración negligente es coherente con lo establecido para las sociedades de objeto comercial. El art. 400 CCom establece que si las gestiones del socio administrador "produjeren perjuicios manifiestos a la masa común, la

${ }^{47}$ No se precisa que el actuar fraudulento sea sancionado penalmente -por ejemplo, como administración desleal (art. $470 \mathrm{~N}^{\circ} 11$ del Código Penal)-, pero una condena penal puede ser suficiente para estimar que concurre una causa grave. Delinquir es algo más que hacerse "indigno de confianza".

${ }^{48} \mathrm{Y}$, naturalmente, sin perjuicio de que esa negligencia pueda constituir de suyo una causal de disolución distinta, como si la negligencia del administrador condujera a la sociedad a la insolvencia (art. 2100 CC). 
mayoría de los socios podrá nombrarle un coadministrador o solicitar la disolución de la sociedad". El legislador complementa así el art. 2072 inc. $2^{\circ}$ CC: la administración manifiestamente perjudicial para los negocios comerciales de la sociedad no permite destituir al socio gestor designado en el contrato social. Pero si la excepción puede explicarse como una mayor deferencia a la discreción empresarial del administrador estatutario, entonces no debiera extenderse al dolo. Y, en efecto, el art. $404 \mathrm{~N}^{\circ} 2$ CCom admite la posibilidad de excluir al socio - eventualmente, el socio administrador estatutario- que aplique los fondos comunes a sus negocios particulares y use en estos de la firma social.

\section{Impedimento permanente o temporal para ejecutar las prestaciones personales con valor específico: hacerse "incapaz de administrar útilmente"}

Puede ocurrir que las razones que condujeron a que el administrador exigiera su designación en el contrato social, desaparezcan con el tiempo. Piénsese en aquel que ha comprometido su prestigio o sus relaciones comerciales para el desarrollo del giro, y que ha decidido ponerlas a disposición de la sociedad únicamente en el entendido de que él habría de administrarla. Puede ocurrir que esta persona pierda ese prestigio o esas relaciones, sea por haber incurrido en algún hecho deshonesto, o simplemente por un acaso. Los demás socios pueden albergar atendibles deseos de liquidar la sociedad, mientras que aquel socio gestor carece ahora de una buena razón para denegarles el acceso a esa administración. Si se opusiera a renegociar la cláusula estatutaria asilándose tozudamente en la intangibilidad del contrato, sería él, no los demás, quienes estarían dando una aplicación oportunista a una previsión que, si protegía la posición del administrador, lo hacía solo en atención a las peculiares características de su inversión -inversión que, en el fondo, ahora ha cesado-. Corresponde entonces la remoción del gestor y la consecuente disolución de la sociedad.

Aquí puede enmarcarse la situación del administrador que padece un impedimento temporal, al menos en algunos casos. Aunque un impedimento de administrar puede también ser -y usualmente será- un impedimento para prestar sus servicios personales, si los demás socios pretenden asumir una gestión interina no hay riesgo alguno para el administrador impedido: el mismo impedimento le pone a salvo de una expropiación oportunista por sus consocios, de forma que no podría razonablemente oponerse a una sustitución temporal del régimen de administración, con el fin de evitar la disolución de la sociedad por aplicación del art. $2073^{49}$. Si, en cambio, el impedimento temporal no obstaría que una eventual administración interina se apropie del valor de la inversión del gestor designado en estatutos (porque le permita acceder a conocimientos técnicos, secretos empresariales u otros, por los que el administrador exigió ser designado de forma

${ }^{49}$ Lo que es especialmente claro cuando los activos tienen algún valor específico, porque entonces mayores serían las razones para evitar la disolución y admitir, como propone Caballero para este caso, la analogía con disposiciones de la Ley $\mathrm{N}^{\circ} 18.046$ que permiten fundar un principio de continuidad de la administración social: CABALLERO, 2014, pp. 369-370. 
privativa e irrevocable), entonces lo razonable es exigir que se acredite la concurrencia de una causa grave y, por disposición del art. 2073, disolver la empresa. Conservarla en un caso como este solo se justificaría si los activos físicos tuvieran mayor valor específico que la inversión de carácter personal, lo que no corresponde a la lógica económica de la organización de sociedades de personas, conforme con el modelo expuesto en estas páginas -aunque en algunos casos pueda acreditarse que la sociedad no se ha formado en esa lógica-.

Nótese que la pérdida de un interés legítimo en administrar por parte del administrador estatutario, puede deberse a causas que le son imputables o no. Si su designación se debió a que sus vínculos familiares le facilitaban contactos comerciales, y más tarde estos vínculos desaparecen (digamos, porque su cónyuge muere), no se indagará si la muerte es imputable al socio administrador, para saber que concurre una causa justa para removerle.

\section{Pérdida del interés en la administración: se es capaz de administrar, pero no "útilmente"}

El análisis efectuado en el capítulo anterior pone de relieve otro tipo de causa grave: la pérdida objetiva de un interés en administrar, por parte de quien se halla designado para esta tarea en los estatutos. Se trata de situaciones en que, sin que el gestor haya cesado de efectuar su inversión en prestaciones personales, esta pierda su valor específico a la empresa social.

Digamos que el socio administrador fue designado por encontrarse en posesión de un secreto empresarial funcional a cierta patente de invención. Puede suceder que, al cabo del tiempo, se extinga esa forma de propiedad industrial o los derechos para explotarla, lo que hace inútil el secreto empresarial. Si entonces el gestor se opusiera a su remoción -lo mismo que si se opusiera a la disolución-, el gestor estaría utilizando oportunistamente una cláusula dictada para un contexto diferente. Asilarse en esa condición sería, en efecto, una conducta oportunista, porque ni la remoción del gestor resta valor a la empresa, ni podrán los demás socios acceder a unos conocimientos que rindan provecho fuera de ella.

Un caso como este hallaría asidero en el adverbio "útilmente". La incapacidad de administrar, caso de causa grave que el art. 2072 inc. $2^{\circ}$ ofrece por vía ejemplar, puede no corresponder a una imposibilidad o dificultad que impida al gestor desarrollar las actividades que venía desempeñando, sino a un defecto en el papel económico que, en la organización de la empresa, juega su misma actividad. Dicho en otras palabras, el gestor es capaz de administrar, es decir, puede continuar realizando aquella inversión en prestaciones personales característica de su posición, pero esa administración ya no es útil a los bienes sociales. De este modo, los demás socios debieran poder renegociar la cláusula y, ante la negativa del gestor, procederá su remoción y la desafectación de los bienes sociales al fin común. 


\section{CONCLUSiOnes}

Las conclusiones de este estudio pueden enunciarse del siguiente modo.

1. La intangibilidad del contrato social, y particularmente de la designación de un socio como administrador privativo, debe adecuarse a sus peculiares características. Se trata de un contrato cuya ejecución en el tiempo requerirá ulteriores modificaciones para ajustarse a las variaciones de circunstancias relevantes, que sería prácticamente imposible prever al momento de contratar. Así, la intangibilidad del contrato exige que la remoción del administrador designado en estatutos se ampare en una causa grave.

2. La presencia de inversiones con valor específico a la empresa societaria, efectuadas por el socio administrador estatutario, si bien no es la única razón que puede explicar su designación, es funcional a las reglas de administración privativa. Comprenderlo así pone de relieve que el socio administrador no es solo un fiduciario respecto de sus consocios, a cuyo interés deba subordinarse, sino que sus facultades de administración son un derecho en cuyo ejercicio tiene un interés propio e independiente del de aquellos.

3. Desde este punto de vista económico, puede considerarse causa grave de remoción aquel hecho que justifica desafectar los bienes sociales a la inversión que el administrador efectúa en términos de prestaciones personales con valor específico a la empresa social, que socios razonables hubieran incorporado explícitamente como causales de remoción. Entre estos hechos puede encontrarse la deslealtad o grave negligencia del administrador; el impedimento permanente o temporal para ejecutar las prestaciones personales con valor específico; y la pérdida del interés en la administración, acaecida por circunstancias objetivas que destruyen el valor específico de aquellas prestaciones.

\section{BIBLIOGRAFÍA}

AlCALDE, Jaime, 2018: “Algunas cuestiones prácticas relacionadas con la liquidación de sociedades de responsabilidad limitada”, en Lorena Carvajal y Ángela Toso (editoras), Estudios de Derecho Comercial. Octavas Jornadas Chilenas de Derecho Comercial, Santiago, Thomson Reuters, pp. 413-453.

Alfaro, Jesús, 1995: Interés social y derecho de suscripción preferente. Una aproximación económica, Madrid: Civitas.

Alfaro, Jesús, 1998: "Conflictos intrasocietarios (Los justos motivos como causa legal no escrita de exclusión y separación de un socio en la sociedad de responsabilidad limitada”, en Estudios de derecho mercantil. Homenaje al profesor Justino F. Duque (Vol. I), Valladolid, Universidad de Valladolid, Secretariado de Publicaciones e Intercambio Científico/Caja Duero, pp. 89-112.

Bello, Andrés, 1887 y 1890: Obras completas (edición hecha bajo la dirección del Consejo de Instrucción Pública), tomos XI y XIII, Santiago: Impresor Pedro G. Ramírez.

Caballero, Guillermo, 2014: "Impedimento temporal del administrador estatutario y régimen supletorio de administración social”, Revista Chilena de Derecho Privado, $\mathrm{N}^{\circ} 22$. Disponible en http://dx.doi.org/10.4067/S0718-80722014000100019. [Fecha de consulta: 13.07.2020]. 
Caballero, Guillermo, 2016: "La remoción de un administrador estatutario", Revista Chilena de Derecho Privado, No 27. Disponible en http://dx.doi.org/10.4067/S0718-80722016000200012. [Fecha de consulta: 13.07.2020].

Caballero, Guillermo, y Pardow, Diego, 2020: "Cuanto más simple, mejor: análisis de las prácticas sobre la constitución y las formas de administración de las sociedades por acciones en Chile", Revista de Derecho Privado, № 39. Disponible en https://doi.org/10.18601/01234366. n39.12. [Fecha de consulta: 21.10.2020].

FERnÁNDEZ de la GÁndARA, Luis, 1977: La atipicidad en derecho de sociedades, Zaragoza: Pórtico. Girón, Jorge, 1976: Derecho de Sociedades, Madrid: Artes Gráficas Benzal.

Jequier, Eduardo, 2014: Curso de Derecho Comercial, Santiago: Legal Publishing/Thomson Reuters. KLEIN, Michele, 1997: El desistimiento unilateral del contrato, Madrid: Civitas.

LópEZ, Jorge, 1987: "Administración y disolución de sociedad civil de responsabilidad limitada”, Revista de Derecho y Jurisprudencia, volumen LXXXIV, No 3. Disponible en http://vlex.cl, cita Westlaw Chile: DD27552010. [Fecha de consulta: 13.07.2020].

Marschak, Jacob, 1968: "Economics of Inquiring, Communicating, Deciding”, The American Economic Review, volumen 58, № 2 .

O'Kelley, Charles, 1992: "Filling Gaps in the Close Corporation Contract: A Transaction Cost Analysis", Northwestern University Law Review, volumen 87, $\mathrm{N}^{\circ} 1$.

Olavarría, Julio, 1956: Manual de derecho comercial (2a edición revisada y corregida por su autor), Santiago: Editorial Jurídica de Chile.

Pantaleón, Fernando, 1993: “Asociación y sociedad. (A propósito de una errata del Código Civil)”, Anuario de Derecho Civil, volumen 46, No 1 . Disponible en https://www.boe.es/ publicaciones/anuarios_derecho/abrir_pdf.php?id=ANU-C-1993-10000500056. [Fecha de consulta: 13.07.2020].

PARdow, Diego, 2007: "Potestades de administración y deberes fiduciarios. Una aproximación analítica a los deberes asociados a la administración de un patrimonio ajeno", en Hernán Corral y María Sara Rodríguez (coordinadores), Estudios de Derecho Civil II. Jornadas Nacionales de Derecho Civil Olmué 2006, Santiago, LexisNexis, pp. 89-112.

Paz-Ares, Cándido, 1991: "Comentario al artículo 1692”, en Cándido Paz-Ares, Rodrigo Bercovitz, Luis Díez-Picazo y Pablo Salvador (editores), Comentario del Código Civil (Vol. II), Madrid, Ministerio de Justicia, pp. 1448-1461.

Puelma, Álvaro, 2006: Sociedades ( $3^{a}$ edición), Santiago: Editorial Jurídica de Chile.

Quesada, María Corona, 1991: Disolución de la sociedad civil por voluntad unilateral de un socio, Barcelona: Bosch.

Reveco, Ricardo, e Iglesias, Juan Pablo, 2019: "El conflicto de interés en el contrato de sociedad y su regulación en el Código Civil bajo el estatuto de responsabilidad contractual. Comentario del caso 'Salinero con Rueda'", Revista Chilena de Derecho Privado, No 33. Disponible en http://dx.doi.org/10.4067/S0718-80722014000100018. [Fecha de consulta: 13.07.2020].

Ribstein, Larry, 2004: "Why Corporations?”, Berkeley Business Law Journal, No 1.

SÁEz, Maribel, 2016: "Reconsiderando los deberes de lealtad de los socios: El caso particular de los socios de control de las sociedades cotizadas", Indret: Revista para el Análisis del Derecho, $\mathrm{N}^{\circ}$ 1/2016. Disponible en http://indret.com/wp-content/themes/indret/pdf/1211_es.pdf. [Fecha de consulta: 13.07.2020].

VÁsquez, María Fernanda, 2015a: “¿Hacia dónde va el derecho societario?: Un análisis desde el derecho comparado y una propuesta preliminar para el derecho chileno", Revista Chilena de Derecho, volumen 42, N $\mathrm{N}^{\circ}$. Disponible en http://dx.doi.org/10.4067/S071834372015000100004. [Fecha de consulta: 13.07.2020]. 
VÁsquez, María Fernanda, 2015b: Sociedades. Comerciantes, empresas, grupos de empresas y otros sujetos del Derecho Comercial (2a edición), Santiago: Thomson Reuters.

Williamson, Oliver, 1985: The Economic Institutions of Capitalism. Firms, Markets, Relational Contracting, New York: Free Press.

Normas jurídicas citadas

Código Civil.

Código de Comercio.

LEY 18.046 sobre Sociedades Anónimas, publicada el 22 de octubre de 1981.

LEY 20.659, Simplifica el régimen de constitución, modificación y disolución de las sociedades comerciales, publicada el 8 de febrero de 2013.

\section{Jurisprudencia citada}

Corte de Apelaciones de San Miguel, sentencia de 14 de agosto de 2008, rol 536-2007. Corte Suprema, sentencia de 12 de julio de 2010, rol 7574-2008.

Corte Suprema, sentencia de 26 de octubre de 2012, rol 1008-2010.

Corte de Apelaciones de Santiago, sentencia de 3 de mayo de 2013, rol 5676-2001.

Corte Suprema, sentencia de 25 de junio de 2013, rol 6846-12.

Corte Suprema, sentencia de 20 de junio de 2014, rol 4341-2013.

Corte de Apelaciones de Antofagasta, sentencia de 29 de abril de 2015, rol 1500-2014.

Corte Suprema, sentencia de 11 de julio de 2016, rol 9046-2015. 